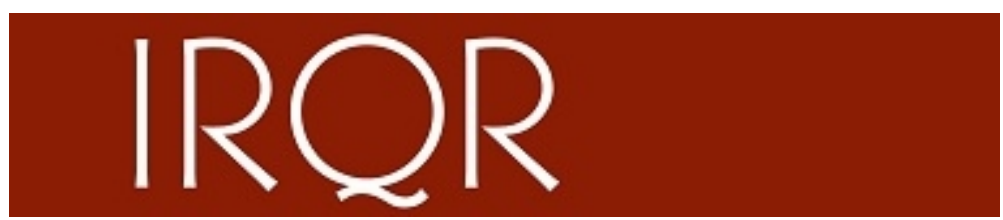

\title{
I, posthuman: A deliberately provocative title
}

\begin{tabular}{|c|c|}
\hline Journal: & International Review of Qualitative Research \\
\hline Manuscript ID & Draft \\
\hline Manuscript Type: & Original Article \\
\hline $\begin{array}{r}\text { Date Submitted by the } \\
\text { Author: }\end{array}$ & $\mathrm{n} / \mathrm{a}$ \\
\hline Complete List of Authors: & Wilde, Poppy; Birmingham City University, School of Media \\
\hline Keywords: & Posthumanism, methodology, MMORPG, cyber, autoethnography \\
\hline
\end{tabular}

\section{SCHOLARONE}

Manuscripts 


\title{
I, posthuman: A deliberately provocative title
}

\begin{abstract}
In this paper, I explore the use of posthumanism as a theoretical framework for autoethnography, and show the methodological tensions of combining these approaches. A posthuman subjectivity rejects notions of the liberal human subject and anthropocentrism by recognising the entanglement of humanity. Acknowledging a posthuman subjectivity means taking account of our constantly intra-connected and transient relationship with our environment and others within it, both human and non-human (e.g. Braidotti, 2013). On the other hand, authoethnographic approaches to research propose self-reflection and personal experience as the basis on which new theoretical insight can be gained. From a critical perspective, "[t]he very idea of autobiography relies on a subject (or a narrator) who is capable of remembering, interpreting and identifying with his or her life story" (Herbrechter, 2012, p.331). Using a posthumanist framework through autoethnographic research means that the "I" is precarious at best; so how and why can we utilise it to explore such a phenomenon as the posthuman? This paper argues that such tensions provide insights into the formation of subjectivity, where "I" is both fallacy and necessity. It explores this methodological tension through an 18-month autoethnographic project that explores my own experiences of gameplay in the massively multiplayer online role-playing game (MMORPG) World of Warcraft (WoW). Using fieldnotes collected during this period, I discuss what a posthuman perspective can bring to an account of my relationship with my avatar, Etyme.
\end{abstract}

\section{Keywords}

Posthumanism, posthuman, methodology, autoethnography, cyber, MMORPG, avatar, gamer. 


\section{I, posthuman: A deliberately provocative title}

\section{Introduction}

When presenting some aspects of my work at conferences I know it will be my methodology that will come under fire. Recently, during my paper at a seminar, someone used Twitter to question whether it was possible to understand something using "only" autoethnography. This standpoint is an oft-encountered critique of the validity of autoethnography (see for example, To, 2015; Ellis et al., 2010) yet always baffles me - we wouldn't say “only” an interview, or ever dismiss participants' experiences in the way some people seem to suggest that we should dismiss our own. However, more than these responses to autoethnography in general, my particular, posthuman use of the methodology elicits, and, it could be argued, requires, further, more complex consideration.

Posthumanism is an expanding field of study, with a variety of theorisations, embodiments and understandings. Hayles' (1999) use of the posthuman suggested that "subjectivity is emergent rather than given, distributed rather than located solely in consciousness, emerging from and integrated into a chaotic world rather than occupying a position of mastery and control removed from it" (p. 291). In my research, the massively multiplayer online role-playing game (MMORPG) avatar-gamer is used as an example of posthuman subjectivity in order to critically consider this phenomenon and analyse how posthuman subjectivity is facilitated and experienced. This research utilises an autoethnographic methodology; however, as I go on to show, there are various tensions within an autoethnographic accounting for posthumanism. If subjectivity is emergent and distributed as Hayles claims, wouldn't an autoethnographic accounting suggest a position of "mastery" in writing about it? In this paper, I explore these tensions, and consider how we might conceive of a posthuman approach to autoethnography that displaces the stability of 
the term "I", even whilst using it. Throughout self-reflexive fieldnotes, the relationship between Etyme (my avatar) and myself demonstrates the capacity of such intra-actions to break down the ontologically distinct avatar and "I." It is with these accounts of a posthuman subjectivity that I argue an autoethnographic account presents anything but a fixed and permanent sense of self awareness, coherence, and individuality. Instead what is demonstrated through the analysis is the intra-dependence of both human and non-human on the other, which takes time to adjust to and theorise:

There is a constant flow between me and Etyme as one and as two. Like any subjectivity this a co-construction. I'm still intrigued though, by just how complicated and blurred the boundaries of self and other have become.

Our entangled subjectivity means that one can only exist through the other, and vice versa. In this paper, I argue that such a posthuman subjectivity is only accessible through accounts of the "I."

The risk in this methodological tension is to present the self as operating from a position of control, knowledge, and anthropocentrism. However, the "grammatical fiction" of "I" (Deleuze, 1991) is both performed and decentred in research contexts that already problematise the liberal subject (p. 95). In this regard, the research hopes to disrupt the humanist centrality of the author, by demonstrating how that " $\mathrm{I}$ " is experienced in a permeable fluidity with a range of different external stimuli.

Below, I begin with some exploration of the theoretical framework of posthumanism in order to uncover its most pertinent factors and to propose my justification for viewing the MMORPG avatar-gamer as posthuman subjectivity. I then explore the tensions of combining these perspectives with an autoethnographic method. In order to explore these arguments, I draw on my fieldnotes throughout to demonstrate the entangled "I" in practice and argue for its insights. 
Autoethnographies are about bringing personal lived experience, rigorous cultural analysis, and emotive forms of representation together in research in order to create accessible texts that provide "evocative thick descriptions of personal and interpersonal experience" (Ellis et al. 2010: n.p.n.). This essay therefore draws on autoethnographic styles, interweaving fieldnotes that capture the lived experience of gaming with an analytical framing and discussion. These fieldnotes were developed by drafting short notes during gameplay to capture key moments without disrupting the game experience, which I then wrote up immediately following the gameplay session. Although I do not utilise a fully narrative, "evocative" style of writing throughout the article, as per To (2015) "I find the 'academic' voice quite useful and helpful in articulating what is needed for a more conceptual discussion" (p. 71). Indeed, in negotiating for more evocative, embodied, and subjective texts, I do not believe that leads to a disavowal of the efficacy of academic texts, which are themselves affectively written (see Ferreday, 2009, p. 31).

\section{Posthuman Paradigms}

Posthumanism "comes in different flavours" with a variety of interpretations, and it is therefore necessary to give some context for the way in which I understand posthuman subjectivity (Roden, 2015, p. 20). The account provided below focusses specifically on the interpretations that align with my use of the term, in order to situate the reader in this context, briefly exploring posthumanism's rejection of the liberal humanist, the disavowal of humans as fixed, stable entities, and the post-anthropocentrism that therefore follows.

In my research I argue that the MMORPG avatar-gamer represents an embodiment of posthuman subjectivity wherein the distinctions between avatar and gamer collapse, forming a notion of an entangled "self," as I explain further below. However, before I focus on this it is important to state that in my use of posthumanism I do not only view the posthuman as one who is technologically mediated. As Tufekci (2012) argues "we were always posthuman," 
that is to say we have always reached beyond the boundaries of our own skin, have always formed relationships with human and non-human others (p. 34). The posthuman view acknowledges and embraces the ontological inseparability of components of "self," "other," and "environment." This forces "a displacement of the lines of demarcation between structural differences, or ontological categories, for instance between the organic and the inorganic, the born and the manufactured, flesh and metal, electronic circuits and organic nervous systems" (Braidotti, 2013, p. 89). I explore this in a technological context, however, as the below aspects of posthumanism demonstrate, this is not integral to posthuman subjectivity.

Whilst relationships with technology form part of the rationale for the posthuman turn, they are far from the only instigating factor and posthumanism has a complex and multifaceted basis informed by the critique of what or who the "human" is and how they "should" behave. Historically, the Enlightenment humanist legacy focussed on "the progress of mankind through a self-regulatory and teleological ordained use of reason and of secular scientific rationality allegedly aimed at the perfectibility of 'Man'” (Braidotti, 2013, p. 37). The humanist focus on autonomy, responsibility and self-determination amounts to an idea that we are "in control," self-regulating, independent beings.

Much of the basic premise of the idea of a human being individual, autonomous and fully in control of their own thoughts and actions has, in more recent years, come into question. This idea of the "rational" being can be linked to the "fiction of autonomous selfhood" (Blackman, 2017). As Blackman (2017) explains, "[t]his fiction is one that assumes that the human subject is ideally bounded, responsible for their actions, selfenclosed and able to develop or enact the capacity for change and transformation through their own agency" (n.p.n.) and as such has "become part and parcel of how we are governed and managed as citizens and populations" (Blackman, 2008, p. 113). The rational, 
autonomous being is therefore a particular construction designed to suit a particular style of governmentality; by making the subject accountable they are also made controllable. As Rose (2001) suggests, "individuals may be made responsible through their individual choices for themselves and those to whom they owe allegiance, through the shaping of a lifestyle according to grammars of living that are widely disseminated, yet do not depend upon political calculations and strategies for their rationales or for their techniques" (p. 57). Thus, by being made accountable for our actions, we must be responsible for their consequences also, which ultimately leads into a self-regulated form of control wherein we are bound by the expectations around us, despite our apparent "freedom."

What the rational subject of humanism does not acknowledge is the much more porous, dispersed, intra-connected aspects of "being" that influence our daily existence. We are constantly entwined with others - human and non-human - around us, and this recognition has led to a renewed understanding of what we are affected by and how we are moved; the way that our embodiment extends beyond our skin shows that the idea of the boundaries that separate "us" from the rest of the world are flawed when taking into perspective our distributed awareness and agency.

This entwinement is experienced in relation to technology to such an extent that "[c]lear distinctions between what is real and what is virtual, where the body ends and technology begins, what is nature and what is machine, fracture and implode" (Toffoletti, 2007, p. 2). When videogaming, for example, the avatar is not only a visual "embodiment" within the gameworld; an affective embodiment is also experienced through the avatar-gamer subjectivity, wherein the gamer is often viscerally moved in response to acts upon the avatar body (see author, 2017, for my work in this area). As Toffoletti (2007) states, digital technologies are becoming more integrated into our everyday existence and bodies, expediting the fundamental reconsideration of how we conceive of the "human" as an 
ontologically distinct category (p. 2).

In a posthuman view, rather than considering the human as the main benefactor in utilising and adapting the "other," be that technology, the environment, animals, etc. we instead consider that rather than these "others" being "extensions," they are in fact implicitly part of what it is to be human: "that what defines humanness or humanicity to use Vicki Kirby's (2011) term is our mixed natures and that we are composite anthropods" (Blackman, 2017, n.p.n.). Barad (2007) similarly claims entities are not distinct but are "entangled" and lack self-contained existence. Barad's (2007) work explores the notion of phenomena as "the ontological inseparability of agentially intra-acting 'components"” (p. 148). In Barad's terms, the human does not operate outside or aside from technology. Instead, rather than two distinct categories of subject and object "inter"acting, components "intra"act, meaning that the ability to act emerges from within entanglements rather than from outside of them (Barad, 2007). Responsibility is distributed and agency emerges as an ability to act within a certain context. This acknowledgement allows us to consider these relationships as a mutual exchange in a more rhizomatic understanding of the perceived importance of the conjoined, intermingled, intra-acting elements, as considered through the following researcher fieldnote, based on my musings around the interplay of theory and practice in my own experiences. It's interesting how the interpretation of the agency of the avatar is perceived in terms of their characteristics, and the ways in which as a player you can either contradict this with your actions or you can work with it. I'm thinking of the ways in which I view things as being appropriate or not to Etyme. On the one hand that could be considered as my agency overpowering that of the avatar, but I don't experience it that way or feel that to be the case. Rather, I would suggest that the game narrative and game environment have agental affects upon my experience which guide me towards particular decisions and choices and away from others. This is in keeping 
with not considering agency to be a possessed quality, but rather as a series of intraacting intra-dependent notions allowing for the emergence of this subjectivity. So the production of the game, the environment and sounds and aesthetic of where Blood Elves start their WoW journey, along with the narrative of the game which tells a complementary story to this, as well as Etyme and "I" our "selves," have all stayed with me and almost unconsciously guide my opinion of Etyme being quite at one with nature. This is reflected in my own choices - e.g. clothing Etyme in browns and greens and greys, organic colours, but under closer inspection I cannot claim that these are my agentic choices. Instead, I have been influenced by all of the other intraacting components.

As a result of this acknowledgement that we are not stable unitary subjects unaffected by our interactions with "others" we have begun to recognise that an anthropocentric attitude is also flawed. As stated above, our reliance on all things "other" demonstrates the entanglement of the "human." How can we claim that we are the centre of the universe, when we rely so heavily on our environment to thrive? Without air, food, water, and shelter as a basic minimum we would not survive. To believe that humans are the centre of the universe is a fallacy, and in recognising our reliance on the "others" around us we can begin to develop a more complex and, hopefully, a less hierarchical understanding of humans' place in the world.

The entanglement that I suggest gamers experience with their avatars and the subjectivity that arises therein is therefore just one example of emotional, physical, and cognitive distribution. Digital games have brought about an interesting development in the study of our engagement with technology. Whilst by no means the only medium that posthuman subjectivity could be explored through, the medium provides a very specific and very explicit aspect of becoming engaged with technology in ways that makes our 
entanglement both obvious and, therefore, hard to deny. In this example, this is a technologically mediated posthuman subjectivity; however, that is not to say that the same principles cannot be applied in other contexts, or that other examples would not prove to be just as illuminating. By using gaming as a context to explore the lived experience of a posthuman subjectivity I am able to consider how we can critically examine the avatar-gamer to see how this subjectivity is constructed and accounted for, in posthuman-autoethnographic ways that acknowledge our multiplicity yet speak from the position of an "I."

Below, I recap some of the pertinent factors of an autoethnographic approach. Considering these in light of the above posthuman framework, I then explore the tensions in a posthuman autoethnography, before going on to justify this approach.

\section{An autoethnographic Accounting}

Ellis et al. (2010) position autoethnography as "one of the approaches that acknowledges and accommodates subjectivity, emotionality, and the researcher's influence on research, rather than hiding from these matters or assuming they don't exist” (n.p.n.). In autoethnographies the writer/researcher is therefore used as a tool, "as an object of description, analysis, and/or interpretation" (Chang, 2008, p. 35), and so it is my (entangled) experiences within the game environment that form the data for my research. Ellis et al. (2010) state that a reflexive ethnography aims to describe the ways in which a deep immersion in a particular cultural context affects the researcher, facilitating articulation and understanding of the impact of environment on being, by acknowledging personal experience as a valid form of data collection and interpretation. I have therefore used the techniques of autoethnography to explore my intimate and affective engagement with a gameworld and with a specific avatar, and in this article I utilise those fieldnotes to examine the ways in which this writing style can accommodate the notion of singularity in the face of multiplicity (Blackman, 2012, p. 2). This therefore utilises my (entangled) experiences but applies them 
to a broader field of study to demonstrate a negotiation of posthuman autoethnography that may be utilised by others exploring this terrain.

Autoethnography's focus on highly subjective, personal, emotional, and embodied forms of knowledge production has aligned it as an "affective" methodology (see, for example, To, 2015), conveying visceral emotions through locating them in embodied experience. However, whilst Paasonen et al. (2015) argue that the use of first person stories is particularly suited to affective work in order to ground and situate affective experiences and to avoid overgeneralisation, there remain issues with the incorporation of the personal, in part down to the question of where the "I" in research comes from. Who is this authorial voice? As Butler (2005) suggests, "[t]he possibility of the 'I,' of speaking and knowing the 'I,' resides in a perspective that dislocates the first-person perspective it conditions" (p. 28). She elaborates:

If I try to give an account of myself, if I try to make myself recognizable and understandable, then I might begin with a narrative account of my life. But this narrative will be disoriented by what is not mine, or not mine alone. And I will, to some degree, have to make myself substitutable in order to make myself recognizable. The narrative authority of the 'I' must give way to the perspective and temporality of a set of norms that contest the singularity of my story. (p. 37)

This is a claim that some might consider to destabilise the whole foundation of autoethnography, as it could be seen to "undermine" the voice of the data. However, I would suggest that just because an "I" is unstable and partial this does not make what this "I" has to say any less of a valid source of data. I would continue as Sundén (2012) before me by using the "I" despite understanding this "I" as fractured and partial, rather than stable and whole. By acknowledging this partiality the research makes clear an epistemological uncertainty as "ways of knowing are shaky, partial, and always in the process of being proved otherwise" 
(Sundén, 2012, p. 171). However, I would suggest that this is, and can always be, the case. Our understanding is always incomplete, as is our knowledge. Nevertheless, "[t]o know oneself as limited is still to know something about oneself, even if one's knowing is afflicted by the limitation that one knows" (Butler, 2005, p. 46).

To (2015) writes that they “employ several different 'voices' or multiple 'I'’s" (p. 71) to present an academic I, a researcher I, a subject I, and a performer I in order to weave together their experiences in a diasporic montage that both utilises the I and employs its multiplicity at once. They explain that "employing an autoethnographic performativity that reflexively positions the possessive 'I' as both locatable and unlocatable offers an intriguing approach [...] [that] aims to subvert and blur the boundaries between subjects, human bodies, and mediated bodies, and motivate rethinkings of relationality, subjectivity, and affective processes" (To, 2015, p. 73, see also Butler, 2005). These tensions with "locatability" are evident through my own "I"s:

Etyme falls from a great height and I gasp. It is completely involuntary, I am in that moment, her, falling, perhaps to her/my death. It is a ridiculous concept because even if Etyme were to die I would be fine, and it would take just moments to run my spirit through the graveyard to find her body and resurrect. Note the my/her complications. The boundaries are blurred. She is not me but she is not not-me. (author, 2017, p. 12)

Autoethnography, therefore, has a complex position in terms of accounting for an "I," As Grant et al. (2013) explain, at times the voice associated with autoethnography can be aligned with positions including "modernism, realism, positivism, phenomenology, and at a broader sociocultural level liberal-humanism" (p. 8). As such, an "I" might be assumed to speak with authority from a particular position on a subject, as ambiguity and complexity might be erased in a literal voice that assumes a stable and authoritative position (Grant et al. 2013). To the contrary, Grant et al.'s (2013) position is that autoethnographies should 
precisely account for the emergence of the "I," as the writing of research demonstrates how subjectivity is produced. The voice is therefore "always provisional and contingent, always becoming" (Grant et al., 2013, p. 8). These arguments are aligned with a more poststructuralist critique and approach to autoethnography, but these arguments are extended further in my own aim of using a posthuman autoethnography.

\section{I, Posthuman?}

As mentioned above, some of the main aspects of posthumanism lie in its disavowal of the liberal human aspects of autonomy, rationality, independence, and control. There are some versions of critical posthumanism that would extend this critique of the liberal human subject to argue that subjectivity is a problematic concept to theorise the posthuman condition through, as its roots are deeply embedded in humanism (see, for one discussion, Callus and Herbrechter, 2012). Herbrechter (2012) explains the critiques of writing from the position of "I" - ranging from Freud's distrust of the "I" due to its influence from unconscious forces to Marx's critique of the subject as being manipulated by ideologies it is unaware of. He also notes post-structuralism's "radicalisation" of "these forms of suspicion, all directed against the idea that subjects are free and competent to give an accurate account of themselves" (Herbrechter, 2012, p. 331).

There are therefore various tensions involved in studying posthuman subjectivity using an autoethnographic methodology. For some, the idea of posthumanism as a movement, turn or philosophy which acknowledges the permeability or entanglement of humans, the ways in which they are constantly shaped by "external" forces and stimuli, including the environment, the non-human, and other people, means that the idea of the "I" is one which is precarious and therefore writing from that position autoethnographically seems contradictory. How can I speak of a "me" when I know that "I" am only what my 
entanglements make "me"? These tensions add a necessary complication to be explored through this article.

It is my belief that none of us are the singular, bounded subjects that liberal humanism would align us with. However, I do not believe it is possible at this stage to fully escape the overthrows of the long history of humanism that has shaped us (as entangled as I believe myself to be, I still speak of "I"). The "I" is the historical way in which humans have come to conceptualise themselves, and as such "the very terms by which we give an account, by which we make ourselves intelligible to ourselves and to others, are not of our making" (Butler, 2005, p. 21). Whilst posthumanism proposes that we critique that separateness from the "other," we cannot yet state that we operate without some sense of "self" appearing, even from the perspective that such a self emerges from an amalgamation of components that collide. As Butler (2005) states, "[n]o one can live in a radically non-narratable world or survive a radically non-narratable life" (p. 59). I am therefore suggesting that the "inescapable fallacy" of the I is indeed at this moment inescapable - it is, as Deleuze (1991) terms it, a "grammatical fiction" but one we need (p. 95). Rather than renouncing subjectivity entirely then, I aim to critically extend "subjectivity" in a posthuman fashion, by acknowledging the multiplicity of beings that contribute to "a" subjectivity at any given time.

It is therefore not my claim that this "I" from which I write is either stable or fixed (see Richardson, 2005, p. 962), nor do I believe it to be free or in a position of power, nor do I even presume the assurance that the "I" is "me." The fieldnotes are not an accurate "representation" of the experience of gaming. Instead, I use the fieldnotes in a performative way as an emergence of the posthuman subject. They become a performative doing refuting a separation between representation and reality, this suggests a "performative" approach wherein the practice of writing the posthuman-"I" produces the posthuman-I (see Barad, 2007). Moreover, they are a posthuman construction in and of themselves, an intra- 
action of Etyme and I, as well as the laptop or phone that I write them on, which also becomes an integral part of their creation:

Ifeel the story of WoW flow far more freely between me and my laptop keyboard than me and the pen. My hands flying across the keyboard in the act of writing up the notes felt much more organic and in time with my hands flying over the keyboard in combat. There, faced with that same screen, the words flow freely through me to the machine, my mind, hands, and machine all in perfect synchronisation, writing the words as they come.

Furthermore, in writing the fieldnotes I "enact the self I am trying to describe" (Butler, 2005, p. 66). Butler explains that by utilising "I" this functions as a performative invocation; the "I" does something, and produces something. This questions the notion of that words and things are separate, and instead suggests an "entangled ontology" - we engage in material-discursive practices that produce different subject positions (see Barad 2007). The fieldnotes are therefore post-anthropocentric despite their reliance on the "I," through demonstrating how that posthuman I is constructed of elements of both human and non-human. As per Butler (2005):

I am authored by what precedes and exceeds me [...] This does not mean that I cannot speak of such matters, but only that when I do, I must be careful to understand the limits of what I can do, the limits that condition any and all such doing. In this sense, I must become critical. (p. 81)

Although "I" am more than "me" I do not feel this should exclude writing about the "self" as long as I acknowledge that self as entangled. I do not feel my material self to be a more influential factor than Etyme's informational self in the posthuman subjectivity that we become and that the fieldnotes partially (in their own fragmented way) embody. This 
approach aligns with recent calls for posthuman methodologies to cultivate a sensitivity to non-humans through a non-hierarchical approach as "one should not assume that human beings are necessarily the most important actor in shaping what happens within an event or situation" (Ash \& Gallacher, 2015, p. 83). For example, Gourlay (2015) explores the material role of the digital device and nonhuman agency to disrupt binaries between text, author, device and user; whilst Allen (2018) adopts an alternative approach to posthuman writing by "offering some visibility upon the dynamics of inscribing and describing realities" through the inclusion of photographs, crossed out text, and notes in order to problematise the humanist self (p. 5).

\section{Entangled with Etyme.}

I am constantly being changed, affected, mediated, by those things - human and non-human - around me. As Butler (2005) affirms: "there is no 'I' that can fully stand apart from the social conditions of its emergence" (p. 7). Therefore, as indicated above, the fieldnotes are a particular aspect of the posthuman-that-is-me. Etyme and I are inseparable in our intra-action and in the fieldnotes: they would not exist without my intra-action with her, and they do not speak only of the human side of our relationship. Even when I move between different pronouns of "I," "she," and "we" the fieldnotes present a narrative that occurs only as a result of myself and Etyme intermingling. Pearce presents some of her research as co-authored between her avatar Artemesia and herself (see, for example, Pearce \& Artemesia, 2009) in a way that is reflective of what occurs in my fieldnotes. The fieldnotes cannot escape the posthuman subject that they represent - or as Barad (2007) might argue, help to create. What I mean by this is that it is through the fieldnotes that my subjectivity with Etyme is made sense of and solidified, and so in some ways comes to be. The following fieldnote demonstrates this analytic and imaginative understanding of self: 
Etyme's not keen on the standing around admiring how good we look - there are things to be done out there! As I write this I realise just how much she is to me, the kind of life she has taken on of her own. This brings home my ambivalence to the idea of whether gamers game as themselves or as their characters. My argument against this way of thinking is that if we have already recognised that the "self" is an unstable and ever changing thing - what on earth makes us think that there is a difference between gaming as our "self" or as our "character"? Every "self" contains different characters already - in one day I am daughter, student, teacher, girlfriend, colleague, friend, customer. Just as these "selves" are entangled with others - daughter with my mother and father, sister with my brother, lecturer with my students - Etyme and I are entangled too. When Etyme and I come together we both become something - together.

The characterisation of Etyme is formed from an intra-action of her actions and my interpretations, but as described above we are each reliant on one another for that "something" that we are - that specific posthuman subjectivity - to occur. This is further enacted through the fieldnotes themselves. As Gibbs (2015) states: "[w]riting is inevitably a process in which subjectivity continually risks itself, finds itself, loses itself, and remakes itself in its dialogic relations with the worlds to which it attunes" (p. 227). This aligns with the notion of the fieldnotes embodying the posthuman subjectivity that emerges from my intra-action with Etyme. We are lost and found through the fieldnotes, the specificities of our individuality are constructed in relation to one other just as the subjectivity we embody together emerges.

Clough (2000) makes an understandable and founded critique of autoethnography, stating that where post-structuralism deconstructs the subject, autoethnography seems to insist on restoring it in order to voice experiences and emotions and claim them as one's own. 
However, as I have stated, in my own methodological use of autoethnography this is not an uncomplicated use of the subject - in "voicing" in-game experiences through the fieldnotes I am not aiming to claim these experiences as my own, or at least not entirely my own. I instead use the fieldnotes as a space to explore the entangled entities that contribute to that experience, as demonstrated below.

As a "hunter" in World of Warcraft I am a ranged attacker, and an enemy must be targeted (indicated as a glowing selection on them) in order for my attacking shots to have a destination. This targeting can happen automatically in game if the avatar is lined up correctly, otherwise it takes a click of a key on the keyboard or the mouse to make this selection. In the following fieldnote, I explain my frustration when trying to attack a group of enemies:
"I neeeed to target something first" Etyme tells me, when I am trying to tell her to attack and she doesn't have an enemy engaged. I mean come on Etyme, we're surrounded! Take your pick! And this is an issue of agency-sometimes in-game Etyme will decide to engage but mostly it is down to me. I still expect her to have some level of autonomy, and this "need to target" presents an annoyance at what is "her" and what is "me”?

Here the shifting states between Etyme and "I" is demonstrated as I again try to negotiate the notion of agency. In the above, although I speak of us as separate entities with differing responsibilities, "we" are surrounded and our distinctions are therefore fluid. But the use of agency above is complicated if we instead consider that "agency is a matter of intra-acting; it is an enactment, not something that someone or something has" (Barad, 2007, p. 178). Rather than either "me" or "Etyme" being individually responsible for our actions these are, as demonstrated by the tensions above, reliant upon our intra-action with one another. If we consider the avatar-gamer as a relational ontology, we can explore this as a "material- 
discursive boundary-making practice" producing "differences out of, and in terms of, a changing relationality" (Barad, 2007, p. 93). From this perspective what is seen as "me" and what is seen as "Etyme" in the above fieldnote is negotiated in reference to one another. Such a relationality implies a more rhizomatic relationship between human and machine, as each is dependent on the other in order to emerge as an entity.

As I focus specifically on the avatar-gamer relationship in my research this could be seen to enact a "cut" in the research. Barad (2007) explains that "entanglements are not isolated binary coproductions" (p. x), and it is important to note that the posthuman subjectivity that I am discussing is constituted by more than just these two entities of avatar and gamer. This subjectivity is also formed by the gameworld, including the computer being played on, and the other gameplayers, to name just a few of the structures and components that feature in the entanglement. However, by focussing on the entanglement of these entities the research demonstrates how an "I" is constructed and experienced in a permeable fluidity with a range of different external stimuli. Most explicitly this construction is demonstrated through relationship with the avatar, but the ways in which the fieldnotes reference other media and move and change between reflection, documentation and analysis as they both describe and critique their descriptions also plays its part, as demonstrated below:

Rereading some of Herbrechter's (2013) book and I am struck again by the ways in which some people might take offence at my research topic and methodology. Some might find it a contradiction - to study posthumanism, the ways in which we are not “one," by using a method which is self-indulgently concerned with "I." If I am not a fixed bounded subject, then from what position do I write an autoethnography?

"The true nature of subjectivity as fragmented, contradictory and irreducible to conscious self-identity, ultimately remains unknowable” (Herbrechter, 2013, p. 205). 
Perhaps though this juxtaposition is what is so necessary, and missing from current debate. What does this posthumanism look like, feel like, to the "human" subject? The inescapable "I" may be a fallacy but it is precisely that - inescapable.

The "I" with which I write this research is an intended posthuman, an "I" which is not just "me" but Etyme too, bound up as we are together, in this world and that. It fluctuates and changes between her, me, we and us as those boundaries undergo their “continuous construction and reconstruction” as per Hayles (1999). I am writing myher-our experiences.

The shifting from reflection to analysis and the reference to further texts demonstrates the breakdown of the author of research as all-knowing, and pays attention to the distribution of agency particularly in online cultures. As my fieldnotes themselves move between different positions of researcher, gamer, analyser etc. a fluid subjectivity is demonstrated throughout. The accounts therefore not only disrupt notions of human / non-human but also demonstrate the disruption of reflection and analysis, and "self" and "other" in scholarly work and the development of ideas as an entangled practice, challenging any sense of authorly authority. As per To (2015) "although my 'staging' speaks from the perspective and pronoun of 'I', this 'I' in fact entangles the voices" - in this case of researcher, gamer, avatar, analyser, to name but a few (p. 73).

\section{Conclusion}

Using the avatar-gamer posthuman subjectivity as a case study, I have complicated the notion of the posthuman subject through the methodological implications of a posthuman "I". I have considered the question of what right we have to speak from the position of an "I" if we are not ontologically distinct. This is undoubtedly a complex and arguably contradictory approach. Nevertheless, as Badmington (2003) states 'the 'post-' of posthumanism does not (and, moreover, cannot) mark or make an absolute break from the legacy of humanism" (p. 
21) and as posthuman as we might be, we are still deeply entrenched in humanistic sensemaking practices. These need to be destabilised and rethought in order to update the concepts to a posthuman, post-anthropocentric accounting. However, I do not think their use is completely at an end. The "I" is used as an indication that as entangled as we are, we are still embodied, and part of our entanglement is still within a humanistic practice of sense-making. This needs to be disrupted to consider what the "I" is, but we can reconceptualise and redefine without ultimately removing these notions from our vocabulary.

Whilst "I" am not only "I" but an amalgamation based on environments, atmospheres, bodies, and societal, political, economic influences "I" still refer to myself as such. I am a posthuman-I, by my own admission and definition, yet I do not refer to myself as a collective nor do I disown the "I" I feel. To do so in my research would be, I believe, disingenuous, as it would suggest an approach that is not my lived experience. More importantly, I doubt it to be the lived experience of any readers of this text. Therefore, the process of using a posthuman-I suggested above allows us to recycle and "update" humanistic aspects of authorly authority, retaining the usage of "I", but adjusting the critical and conceptual underpinnings that influence how we understand and interpret the self. To radically depart from any self-referential practices seems to be, frankly, both unlikely and ultimately unhelpful. Some more radical posthumanists might argue that this viewpoint only serves to re-establish the "I" as a locus of control and humanist accountability. However, I believe that using the "I" whilst understanding and recognising our entanglements, the distribution of our agency and the emergence of self as being contingent on "others", becomes a critically reflexive practice.

Despite its reliance on the "I" this methodology is therefore nevertheless informed by a form of "posthuman epistemology" by drawing on "non-human experience as site of knowledge" (Ferrando, 2012, p. 10) through the incorporation of the avatar and game, 
thereby constructing knowledge that is based in posthuman experience. This links to broader claims that "methodological sensitivity is not an entirely human affair, and requires many eyes and ears - human and nonhuman - which can work with traces, gaps, absences, submerged narratives, and displaced actors in order to shape a form of mediated perception" (Blackman, 2015, p. 25). This article therefore serves as a useful example of how autoethnography can function in cyberspaces such as gameworlds, taking into account the specificities of the cyber (e.g. avatar, game, hardware, etc.) and integrating them into the autoethnographic practice and ultimately the research that is produced. From a posthuman perspective, we must account for the specific entanglements, phenomena, and subjectivities that arise through this cyber intra-action through those digital and machinic elements, and how they shape the "I" that we are.

The methodological implications of a posthuman and cyber autoethnography suggested in this article have therefore negotiated some of the provocations and potentials of using the "I" in an entangled way. The use of a posthuman-I has conceptualised and delivered a difficult methodology that emerges from an understanding of the tensions between these positions, but nevertheless justifies the posthuman-I as contingent, contradictory, and multiple. This provides a posthuman subject that is both radical but accessible - radical in its multiplicity, in the incorporation of different subject positions, and in the negotiation of an entanglement - but accessible in a narrative form and through the use of the "I" - that historic fallacy of selfhood that we nevertheless rely on to make sense of our experiences. 


\section{Reference}

Allen, S. (2018). The Unbounded Gatherer: Possibilities for posthuman writing-reading. Scandinavian Journal of Management [online]. Retrieved from https://doi.org/10.1016/j.scaman.2018.07.001

Ash, J. \& Gallacher, L. A. (2015). Becoming attuned: Objects, affect, and embodied methodology. In M. Perry and C. L. Medina (Eds.), Methodologies of embodiment: Inscribing bodies in qualitative research (pp. 69-85). Oxon, UK: Routledge.

Badmington, N. (2003). Theorizing posthumanism. Cultural Critique 53, 10-27.

Barad, K. (2007). Meeting the universe halfway: Quantum physics and the entanglement of matter and meaning. London, UK: Duke University Press.

Blackman, L. (2008). The body. Oxford, UK: Berg.

Blackman, L. (2012). Immaterial bodies: Affect, embodiment, mediation. London, UK: Sage.

Blackman, L. (2015). Researching affect and embodied hauntologies: Exploring an analytics of experimentation. In B. Knudsen \& C. Stage (Eds.), Affective methodologies (pp. 25-44). Hampshire, UK: Palgrave Macmillan.

Blackman, L. (2017). "Loving the alien”: A post-post-human manifesto. Subjectivity [online]. Retrieved 13 March 2017 from http://link.springer.com/article/10.1057/s41286-016-0022-6

Braidotti, R. (2013). The posthuman. Cambridge, UK: Polity Press.

Butler, J. (2005). Giving an account of oneself. New York, NY: Fordham University Press.

Callus, I. \& Herbrechter, S. (2012). Introduction: Posthumanist subjectivities, or, coming after the subject.... Subjectivity, 5(3), 241-264.

Chang, H. (2008). Autoethnography as method. Walnut Creek, CA: Left Coast Press. 
Clough, P. (2000). Autoaffection: Unconscious thought in the age of teletechnology. London, UK: University of Minnesota Press.

Deleuze. G. (1991). A philosophical concept.... In E. Cadava, P. Connor \& J. Nancy (Eds.), Who comes after the subject? (pp. 94-95). London, UK: Routledge.

Ellis, C., Adams, T. E. \& Bochner, A .P. (2010). Autoethnography: An overview. Forum: Qualitative Social Research [online] 12(1). Retrieved from http://www.qualitativeresearch.net/index.php/fqs/article/view/1589/3095

Ferrando, F. (2012). Towards a posthumanist methodology. A statement. Frame - Journal for Literary Studies, 25(1), 9-18.

Ferreday, D. (2009). Online belongings. Oxford, UK: Peter Lang.

Gibbs, A. (2015). Writing as method: Attunement, resonance, and rhythm. In B. Knudsen \& C. Stage (Eds.), Affective methodologies (pp. 222-236). Hampshire, UK: Palgrave Macmillan.

Gourlay, L. (2015). Posthuman texts: nonhuman actors, mediators and the digital university Social Semiotics, 25(4), 484-500.

Grant, A., Short, N. P. \& Turner, L. (2013). Introduction: Storying life and lives. In A. Grant, N. P. Short \& L. Turner (Eds.), Contemporary British autoethnography (pp.1-16). Rotterdam, Netherlands: Sense Publisher.

Hayles, N. K. (1999). How we became posthuman. London, UK: The University of Chicago Press.

Herbrechter, S. (2012). Posthumanism, subjectivity, autobiography. Subjectivity, 5(3), 327347.

Herbrechter, S. (2013). Posthumanism: A critical analysis. London, UK: Bloomsbury. 
Paasonen, S., Hillis, K. \& Petit , M. (Eds.) (2015). Networked affect. Massachusetts, MA: MIT Press.

Pearce, C. \& Artemesia. (2009). Communities of play. Cambridge, UK: MIT Press.

Richardson, L. (2005). Writing: A method of inquiry - part 1: qualitative writing. In N. Denzin \& Y. Lincoln (Eds.), Handbook of qualitative research. $3^{\text {rd }}$ ed. (pp. 959-967). Thousand Oaks, CA: Sage.

Roden, D. (2015). Posthuman life. Oxon, UK: Routledge.

Rose, N. (2001). Governing “advanced” liberal democracies. In A. Barry, T. Osborne \& N. Rose (Eds.), Foucault and political reason (pp. 37-64). London, UK: Routledge.

Sundén, J. (2012). Desires at play: On closeness and epistemological uncertainty. Games and Culture, 7(2), 164-184.

To, N. (2015). Diasporic montage and critical autoethnography: Mediated visions of intergenerational memory and the affective transmission of trauma. In B. Knudsen \& C. Stage (Eds.), Affective methodologies (pp. 69-93). Hampshire, UK: Palgrave Macmillan.

Toffoletti, K. (2007). Cyborgs and barbie dolls: Feminism, popular culture and the posthuman body. London, UK: I B Tauris \& Co.

Tufekci, Z. (2012). We were always human. In N. L. Whitehead \& M. Wesch (Eds.), Human no more: Digital subjectivities, unhuman subjects, and the end of anthropology (pp. 33-47). Boulder, CO: University Press of Colorado.

Wilde, P. \& Evans, A. (2017). Empathy at play: Embodying posthuman subjectivities in gaming. Convergence (Online First). Retrieved from https://doi.org/10.1177/1354856517709987 